\title{
Higher Education in Light of Covid-19 Pandemic: The Role of Educational Technology
}

\author{
Mohammed Mispah Said Omar ${ }^{1} \&$ Abdelghani Echchabi ${ }^{2}$ \& Abdullah Mohammed Ayedh ${ }^{3}$ \& Salim Al- \\ Hajri $^{4}$ \\ ${ }^{1 \& 4}$ College of Business Administration, A’Sharqiyah University, Sultanate of Oman \\ ${ }^{2}$ Business Division, Dubai Men's College, Higher College of Technology, United Arab Emirates \\ ${ }^{3}$ Faculty of Economics and Muamalat, Islamic Science University of Malaysia, Malaysia \\ Correspondence: Abdelghani Echchabi, Higher College of Technology, United Arab Emirates. \\ Email: aechchabi@hct.ac.ae
}

Doi: 10.23918/ijsses.v8i1p124

\begin{abstract}
The aim of the paper is to discuss and analyze the effect of the Corona Virus (COVID-19) pandemic on the higher education sector across the word. In addition, it aims to highlight the challenges and opportunities it has created for the Higher Education Institutions (HEIs) by migrating to the online learning mode. Therefore, the current study has underlined various areas of technology used in the higher education sector transformation enabling HEIs' a smooth migration towards the online/distance delivery mode, that was mainly due to the COVID-19 pandemic and its repercussions. The findings revealed that the COVID-19 pandemic and its repercussions have provided HEIs the opportunity to be operating through online learning mode, while other HEIs have significantly struggled through the process, with some of them were required to postpone their classes till the overall conditions allow them to resume physical face to face classes. The findings have significant implications suggesting that even if the COVID-19 pandemic situation is cleared, HEIs are highly advised to consider the implementation of online learning mode, or at least the hybrid mode of learning. Moreover, HEIs are highly advised to re-think about their budgets allocations and re-adjust them based on the experience and outcomes of the COVID-19 pandemic.
\end{abstract}

Keywords: Educational Technology, Blackboard, COVID-19, Corona Virus, Higher Education, Online Learning

\section{Introduction}

The Corona Virus (COVID-19) in its current form was first identified in the Wuhan region of China in December 2019. As of June $26^{\text {th }}$, 2020, COVID-19 affected nearly 10 million people and nearly 500,000 deaths around the world ${ }^{1}$. As such, this virus was given serious attention by all the affected countries to contain it and find a vaccine that would stop its spread. In the initial stage of the virus spread, activities of most sectors continued as usual with extra safety precautions recommended to protect individuals and contain the spread of the virus.

Received: January 25, 2021

Accepted: March 10, 2021

Omar, M.M.S., \& Echchabi, A., Ayedh, A.M., \& Al-Hajri, S. (2021). Higher Education in Light of Covid-19

Pandemic: The Role of Educational Technology. International Journal of Social Sciences \& Educational Studies, $8(1), 124-136$.

${ }^{1} \mathrm{https}: / /$ www.worldometers.info/coronavirus/ accessed online on June $26^{\text {th }}, 2020$ 
However, with the fast spread of the virus, and the significant increase in the number of people affected and the number of deaths, most of the countries decided to lockdown their borders, and apply full lockdown of activities within the country, except for vital activities. In this regard, most of the companies required their employees to work from home (WFH), and individuals were instructed not to leave home unless for an emergency or for buying necessary grocery or to seek medical assistance.

These rules also applied to higher education institutions (HEIs), where they employees were required to $\mathrm{WFH}$, and their teaching faculties to teach from home (TFH) resorting to online learning, which significantly transforms the way HEIs operate (Alshamsi, Mohaidat, Al Hinai, \& Samy, 2020). Accordingly, the objective of the current study is to examine and discuss the effect of COVID-19 pandemic on the higher education sector around the world, and the transformation it experienced from technology perspective. In addition, it aims at highlighting the challenges and opportunities it has created for the HEIs by migrating to the online learning mode.

In order to discuss and analyze the effect of the COVID-19 pandemic on the higher education sector across the world, the opportunities and challenges of migrating to the online learning mode will be measured and compared between what higher institutions used during COVID-19 pandemic and the actual challenges faced by educators "teachers", highlighting the main technologies tools and platforms that allowed the participants in this process to smoothly transit to the delivery of online learning within a short period of time. The study also reflects upon the test and measurement theory formally developed by Compeau and Higgins (1995), as it looks at the standard assessment's development and measurement methods in contrast to the latest technological advancements introduced and their assessments' development aspects during the COVID-19 period.

Although this type of studies is relatively new due to the current COVID-19 pandemic, most of the studies in the prior literature had addressed the impact of COVID-19 in HEIs in local contexts (see for example Sweden). In contrast, this study is addressing the challenges and opportunities of migrating to the online learning mode from a global perspective as this phenomenon has affected all education sectors with no exception.

The remaining part of the paper is organized as follows: Section two briefly reflects on the migration to online learning due to COVID-19 pandemic. Section three discusses the role that educational technology played in the transition period to online learning, by highlighting the main technologies that were used in the process and their contribution to the smooth transition and delivery of online learning. Section four discusses some educational approaches that are compatible and useful when conducting online classes. Section five discusses the challenges and opportunities raised due to the COVID-19 pandemic and the migration to the online mode of learning. Finally, section six summarizes the outcomes of the study and provides practical recommendations, as well as directions for future studies in this area.

\section{COVID-19 Pandemic and the Migration to Online Learning}

HEIs around the world attempted to respond to the sudden urge to migrate from the face-to-face classroom delivery mode to the online/distance delivery mode. This migration notably required a significant amount of technological infrastructure and logistics preparedness, besides the staff readiness and ability to use the 
required technological tools (Al Lily, Ismail, Abunasser, \& Alqahtani, 2020). It was remarkably obvious that HEIs that had a short-term vision heavily oriented towards the use of technology, were at an advantage when the migration was most required. These HEIs had already invested significantly in educational technology and have substantially trained their staff and students on their usage (Alshamsi et al., 2020). Other HEIs have gone further by implementing online learning to different extents, which renders the migration to fully online learning smooth and efficient.

It is noteworthy that the efficient usage of the education related technology tools requires that all the components of the HEIs become familiar and proficient in using it (OECD, 2016). This includes the top management, student affairs and academic affairs, information technology and learning and management systems departments, the teaching faculties, as well as the students. Hence, the proper trainings and awareness programs must be put in place for the online experience of teaching and assessments to be successful. In addition, comprehensive guides and links need to be provided to all HEIs' staff and students, to increase their understanding of the functioning and usage of each of the existing tools.

Furthermore, the successful and smooth migration to the online delivery mode of teaching required cooperation and support from other sectors, particularly the telecommunication sector (OECD, 2020). In this regard, the telecommunication industry in many countries have increased their internet speed, or made it available to customers at lower rates, for all students to have access to fast internet connection which allows them to attend their classes and take their assessment in convenient conditions. These facilities have also helped the teaching faculties when the WFH and TFH stage was launched. Furthermore, these telecommunication companies have also lifted the restrictions they use to usually have on some communication tools like Zoom for example that played a significant communication and connection role during the peak of the COVID-19 breakout, and the full lockdown period that was imposed in many countries (He and Harris, 2020). Hence, for the online/remote education to function properly at the higher levels, collaboration between various economic sectors is highly required.

\section{Educational Technologies}

\subsection{Blackboard Learn}

Blackboard Learn (BBL) is a virtual LMS platform for teaching and learning, community building and development, as well as information and knowledge sharing between users, developed in 1997, by Blackboard Inc., an education technology company based in Washington (Bradford, Porciello, Balkon \& Backus, 2007). BBL is one of the most popular and widely used LMS tools among universities globally (Alokluk, 2018).

BBL is like a "one stop service center" that provides a rich variety of learning and teaching tools that are most used in higher education. Through its Blackboard Collaborate (BBLC) tool, the teaching faculties can give a live interactive face to face class, which can also be recorded and shared with the users for posterior usage. During the BBLC sessions, the students can discuss, make presentations, share their screens and applications, or even solve problems on the whiteboard, all this with permission from the course instructor. BBLC also allows the creation of breakout groups, where students can be grouped together for personalized discussions of case studies, projects, or peer assessments. Moreover, BBLC 
provides an interesting "polling" tool where the instructor can consistently pose questions to the students in multiple choice form, to check their understanding of the taught topics.

BBL also provides remarkable assessment tools where students can take exams on the platform, and later the exams can be graded, and grades shared online with the students together with constructive feedback on their performance. Similarly, the students have the possibility to submit their project, case studies and other assignments, online through BBL, the assignments are automatically checked for plagiarism even before the instructor grades then and shared the grades and feedback online on the same platform. This makes the whole process of conducting the exam, grading it, and then sharing the grades and feedback smoother and more efficient for all participants.

Furthermore, BBL is a convenient method for sharing teaching materials and other resources with students, whereby multiple material folders can be created for different courses, and the instructor can always update them whenever need arises. Similarly, the platform provides a possibility for the users to share knowledge, information, and opinions through the "discussion boards" which can be created by the instructor and shared with students.

\subsection{Respondus Lockdown Browser and Monitor}

Respondus lockdown browser (RLDB) and monitor (RLDM) are two closely related products developed by Respondus, which is an American company that specializes in the development of assessment applications for the education, training, and certification institutions ${ }^{2}$. RLDB which was first launched in 2000, is a customized browser that locks down the testing environment within an LMS tool. RLDB allows the students to launch their assessment in the full-screen mode, but it prevents them from navigating away from the assessment page or accessing other applications while the test is in progress. RLDB also prevents actions like copying and pasting, right-clicking, screen capturing, messaging, or printing.

On the other hand, RLDM builds upon RLDB and its strengths and power by automatically activating the web-camera of the assessment taker during non-proctored exams on RLDB. The full assessment session is then recorded, analyzed, and shared with the instructor and other eligible users. Before the assessment starts, the exam taker is required to go through a startup and identification, where a photo and a video of him/her is taken in the correct camera frame, together with a photo of the student identification card, and a video of the exam environment. Once the assessment starts, the video recording starts and continues until the student submits his/her answers. The video records are subsequently processed for analysis, and the time it takes depends on the number of students taking the exam. The final analysis of the exams video records is then saved and made accessible to the instructor and any eligible users. The analysis highlights and flags any suspicious actions by the exam taker to be reviewed by the instructor. Accordingly, an overall level of risk and review requirements are assigned depending on the number of flags, and the length of the highlighted video segments.

${ }^{2}$ https://web.respondus.com/about/ accessed online on June $25^{\text {th }}, 2020$ 


\subsection{Moodle}

Modular Object-Oriented Dynamic Learning Environment (Moodle) is an online learning platform developed by Martin Dougiamas in August 2002 to provide educators, administrators, and learners with a system to create personalized learning environments (Novac, 2014). Moodle's focus is on interaction and collaborative development of content, as well as the continuous improvement of the whole platform (Thakur, 2015). One of the most important advantages of Moodle is its cost-effectiveness, since the basic features and downloads are a provided free of charge, and nominal payment to get extra features is minimal.

Moodle has been popular in many countries' higher education circles but has been heavily used especially during the COVID-19 peak period. The platform is user friendly and easy to access and operate as it has a simple and straightforward interface that allows users to easily access the required functions. Moodle provides a wide variety of functions to teaching faculties and students. However, Moodle has been mainly used to upload and share teaching materials and resources between teaching faculties and students, as well as information and opinions sharing through forums.

A major weakness of Moodle is that it does not provide the option to teach students live. This shortfall is especially weighing on technical and practical courses that usually require significant demonstration of problem solving and analytical skills. In such courses, instructors need to timely assess students' understanding by evaluating their feedback and reaction to new knowledge, to build their skills gradually and successfully. Hence, Moodle is not effective from this perspective.

\subsection{Zoom}

Zoom is one of the leading international video communication tools, provided by Zoom Video Communications, Inc., an American communications technology company, founded back in April 2011. Since its inception, Zoom has been widely used worldwide across various sectors and industries. Nevertheless, its usage and adoption boomed during the COVID-19 surge due to the significant increase in the demand for video-conferencing tools as the world shifted to WFH during the global lockdown period to contain the spread of the virus. In this regard, reports have shown that the estimated net worth of its founder has increased by more than $\$ 4$ billion since the COVID-19 crisis started ${ }^{3}$.

Zoom provides a wide variety of options and functions related to videoconferencing to users. In the case of HEIs, it has been mainly used for live class teaching and recording either on the cloud or on the computer. This allows the users to access and review the recording any time after the class. In addition, Zoom provides the possibility to create breakout rooms within the same session, where small groups of students for instance can be joined together to discuss a specific topic, case study or project. Furthermore, the application was exceptionally useful in advising and mentoring students on various academic and general matters through one-to-one sessions. Zoom was often used to proctor assessments for students writing online exams through other learning management systems (LMS) tools. On the other hand, Zoom

\footnotetext{
${ }^{3}$ https://www.theguardian.com/technology/2020/mar/31/zoom-booms-as-demand-for-video-conferencing-techgrows-in-coronavirus-outbreak accessed online on June $22^{\text {nd }}, 2020$.
} 
was also used for the common video-conferencing purposes, by connecting higher education employees either on a one-to-one basis, or through group meetings.

\subsection{Nearpod}

Nearpod is an interactive web-based learning platform created in 2011 by Nearpod Inc., an educational technology company based in the United States of America. The platform allows students to actively engage with their lecturers during the class sessions (Sanmugam, Selvarajoo, Ramayah \& Lee, 2019). Using Nearpod, lecturers can create and share presentations that could contain a combination of different categories of contents. These presentations are shared live with the students through a unique code at the start of each session. Once the students access the presentation, they will be able to follow the presentation, which is controlled by the instructor (Sanmugam et al., 2019). The students can then interact with the instructor through various tools incorporated in the presentation, including open ended questions, quizzes, polls, collaborate boards, VR field trips, fill in the blanks, matching pairs, and draw it ${ }^{4}$. These multiple tools contribute to developing diversified content that also allow the instructors to assess the level of learning and understanding of the students for possible adjustments in learning methodologies or shifting of the focus on different sub-topics.

\subsection{Kahoot}

Kahoot was founded in 2012 by Morten Versvik, Johan Brand, and Jamie Brooker who, in a joint project with the Norwegian University of Science and Technology (NTNU), teamed up with Professor Alf Inge Wang, and were later joined by entrepreneur Asmund Furuseth". Kahoot inspires to make learning "fun" and "awesome" to students through an innovative gamification approach (Lin, Ganapathy, \& Kaur, 2018).

In the online/distance learning and teaching mode, since the students are remotely attending the class, it is very crucial to have tools that would keep the students engaged, interactive, and concentrated during classes. In this regard, Kahoot provides a combination of quizzes, polls, and word cloud among others, to keep the students engaged throughout the class, since these tools can be used for ice-breaking, knowledge check, or even for pre-assessment of knowledge. The instructor can simply create a set of various types of questions on the Kahoot platform and share the questionnaire code with students and any other participants that can access the questions and answers them as the instructor progresses in the class delivery. The students' answers together with their ranking vis-à-vis the whole group will be immediately displayed after each question. As such, this platform and this approach not only keeps the students engaged, but also creates competition between them, and incites them to learn more, so that they can answer correctly and lead the group ranking, which would ultimately contribute to the improvement of their overall final class performance.

\subsection{Microsoft Teams}

In 2016 Microsoft introduced "Microsoft Classroom" as an online blended learning platform for schools, to simplify grading assignments and student communication. One year later Microsoft has announced

${ }^{4} \mathrm{https}: / /$ nearpod.com/l/higher-ed/ accessed online on June $25^{\text {th }}, 2020$

${ }^{5}$ https://kahoot.com/company/ accessed online on June $22^{\text {nd }}, 2020$ 
Microsoft Teams (MT) platform to mainly service businesses including functions like chat, video meetings, file storage, and application integration. In 2017, Microsoft announced replacing Microsoft Classroom with MT. Under MT, the education features and functions allow teachers to supply, provide feedback, and grade student assignments submitted via MT using the Assignments tab, available to Office 365 for Education subscribers (Martin \& Tapp, 2019). On the other hand, quizzes could be assigned to students through an integration with office forms. The popularity of MT significantly increased recently, particularly during the COVID-19 outbreak. In this regard, Microsoft recorded a 20 million active users of MT in 20196. On March 2020 in the early stage of COVID-19 and during the global lockdown, the users of MT reached 44 million and move up to hit 75 million daily active users ${ }^{7}$.

The most important advantage of using MT for education is that most of the users -either teachers or students- are familiar with its interface and functions. Secondly, MT is part of the various Microsoft applications, thus synchronizing and using MT with other Microsoft applications is easy and efficient. In addition, MT is free for the Office 365 subscribers. Nevertheless, some users argue that issues like difficult transition from Outlook, or the files' structure tend to confuse them. Furthermore, permission settings, and limited flexibility could also lead to manual replications ${ }^{8}$.

MT played an essential role in the higher education by providing both synchronous and asynchronous learning methods. MT provides the option of online live classes in real time, which provides the opportunity of effective interaction between lecturer and students. Furthermore, MT allows team leader (i.e., lecturers) to video-record classes in the Microsoft cloud stream, allowing users to view and download the class videos for review and revision purposes. In addition, assignments, quizzes, files sharing, students' attendance tracking, and chatting activities are all available in MT.

\subsection{Camtasia}

Camtasia is a video recording and editing software, created, and published by TechSmith in October 2002, for creating innovative tutorials and presentations videos. This can be performed via a direct recording plug-in to Microsoft PowerPoint, and can be instantly shared on YouTube, Vimeo, Screencast, or the online video course ${ }^{9}$.

Camtasia is most useful for cases where the classes are not delivered in real time live basis. Camtasia is also beneficial where the created videos can be used as supplementary resources for courses delivered on a live basis. In both cases, the videos created through Camtasia conveys significant knowledge to learners in an innovative way, that would keep them concentrated throughout the video session.

\footnotetext{
${ }^{6} \mathrm{https}: / /$ www.zdnet.com/article/microsoft-says-it-has-20-million-daily-active-teams-users/ accessed online on June $24^{\text {th }}, 2020$

${ }^{7}$ https://www.wsj.com/articles/microsoft-aims-to-dominate-technology-at-work-starting-with-those-video-calls11591108757 accessed online on June $20^{\text {th }}, 2020$.

${ }^{8}$ https://storyals.com/blog/pros-and-cons-of-microsoftteams\#: :text=Limited $\% 20$ flexibility $\% 20$ can $\% 20$ lead $\% 20$ to,the $\% 20$ structure $\% 20$ ready $\% 20$ from $\% 20$ start.\&text=C urrently $\% 2 \mathrm{C} \% 20$ the $\% 20$ building $\% 20$ blocks $\% 20$ of,time $\% 20$ wasted $\% 20$ doing $\% 20$ manual\%20replications. Accessed online on June $23^{\text {rd }}, 2020$.

${ }^{9}$ https://www.techsmith.com/video-editor.html accessed online on June $25^{\text {th }}, 2020$
} 


\subsection{SoftChalk}

SoftChalk (SC) is an e-learning content authoring software that allows the creation, management and sharing of interactive online learning content. SC was developed and launched by SoftChalk, LLC in 2002 to provide better tools for creating interactive learning content for delivery in learning management systems. One aspect of SC is free, public, and open resources, where the users can share learning content licensed under a creative commons license (Hai-Jew, 2013).

SC supports the creation of more than 22 types of different content types including HotSpot Image Quizzes, Crossword Image Puzzles, Jigsaw Puzzles, Drag and Drop Images Labeling, Interactive Timeline, and Flash Cards, beside the standard quiz question types (Information Resources Management Association, 2015). It is noteworthy that SC can be easily integrated with common LMS tools, where content developed using SC can be efficiently delivered and shared, and even simultaneously on multiple platforms.

\subsection{Google Meet}

Google Meet (GM) is a video communication service developed by Google LLC, the American multinational technology company in October 2019. GM is available for free, where users who have a Google account could have a video meeting with up to 100 participants. On the other hand, upgrades to $\mathrm{G}$ Suite (GS) accounts are also possible for a negligible fee.

Both GM and GS have been effectively used for online learning by holding live video classes, especially during the COVID-19 outbreak. The fact that GM and GS are provided for free or for a small fee made them relatively popular and increased their spread within the higher education circles.

\section{Learning and Teaching Methods Adjustment}

\subsection{The Flipped Classroom Model}

The flipped classroom (FC) approach is known by various names including the inverted classroom, flipped learning, or more simply, the flip (Arnold-Garza, 2014). In the FC framework, students are required to complete the pre-class preparatory work and corresponding activities, which is usually in the form of short online videos or readings, to gain understanding of the topics' content. The face-to-face session is then used for problem solving, application of learning, synthesis, and collaboration with peers (Ozdamli \& Asiksoy, 2016).

The FC model focuses on four dimensions reflected by the FLIP acronym, where "F" stands for flexibility, "L" for learning culture, "I" for intentional content and "P" for professional educator (Ozdamli \& Asiksoy, 2016). The flexibility dimension reflects the availability of ample time and space options for learners, since learning under FC occurs on an extended span of time and space and using variety of tools. On the other hand, the learning culture refers to the shift from the teacher-centered framework to the studentcentered approach, which is in the core of the FC model. Intentional content is there the instructors identify the course content that they should teach directly to students, and the material and topics that students can explore independently with minimum supervision from their teacher before coming to the face-to-face 
class. Finally, the professional educator aspect implies that the responsibility of educators using FC is greater than those using the traditional methods, since a major portion of learning occurs remotely even though with some degree of supervision from the instructors under the FC model.

This approach allows the students to gain knowledge and understanding at their own pace and using tools and resources that are most convenient to them but is also gives them the opportunity to be actively engaged with the course content, which equips them with even deeper and better understanding of the intended topics. In addition, the learners are provided with timely and richer feedback on their learning, since they join the face-to-face class with prior knowledge and understanding of basic concepts, which they apply on complex problems and group discussions (Smallhorn, 2017). Hence, FC has provided significant improvements to the traditional classroom setting, which became even more significant with the increasing access and use of computerized and web-based learning methods (Urfa, 2018).

The role that FC plays in higher education appeared more important as universities globally were forced to migrate to the online mode of course delivery during the COVID-19 pandemic, where students in most universities internationally were attending classes remotely. For learning to be effective under these circumstances, it is crucial to use educational tools that increase students' engagement and interaction. FC notably one of the tools that performed excellently during this period.

\subsection{Gamification of Knowledge}

Gamification which refers to the "the use of game design elements in non-game contexts" (Deterding, Dixon, Khaled, \& Nacke, 2011, p. 9) has become one of the most notable technological developments for human engagement across settings and sectors (Majuri, Koivisto, \& Hamari, 2018). In the specific case of higher education, gamification techniques are commonly used to increase learners' motivation and engagement throughout the learning process (Alomari, Al-Samarraie, \& Youssef, 2019). The trend of gamification usage in higher education has been increasing in the last few years, benefiting from the technological advancements and the creation of enormous, digitalized learning tools and platforms (Majuri et al., 2018).

Gamification in higher education covers a wide range of tools and methods that represent added incentives for students to remain engaged and interactive throughout the learning process, but also to provide them timely feedback that will help them improve their understanding and learning experience (Hung, Zarco, Yang, Dembicki, \& Kase, 2018). In addition, gamification-based teaching practices were found to have a positive impact on students' achievements, attitudes towards learning (Yildirim, 2017).

Common gamification techniques in higher education include points, status, collaboration ranks, prizes, badges, virtual currency, leaderboards, scoreboards, narratives, avatars, stamps, tokens, challenges, unlockable content, progress bars, levels, and feedback (Dichev \& Dicheva, 2017). These techniques apply differently for different scenarios and audiences, and their implementation depends largely on their intended outcomes and the course intended outcomes. However, they are all compatible with the online delivery mode (Antonaci, Klemke, \& Specht, 2019). 


\section{Challenges and Opportunities}

Since its surge, COVID-19 caused serious damages to human lives, and health globally. The virus also caused significant losses to governments, companies, and individuals internationally, as the world was forced into lockdown, especially during the peak spread period of the virus. Accordingly, many HEIs around the world resorted to online learning as a temporary solution to survive through the COVID-19 pandemic (UNDP, 2020). This transition created new opportunities for HEIs and their students but resulted in additional issues and challenges as well.

One of the major challenges when using the online mode of course delivery is the reliability of the assessments, since the students take their exams remotely under different styles of online proctoring-if any (Gonzalez-Gonzalez, Infante-Moro, \& Infante-Moro, 2020). In this regard, there is several possibilities offered to HEIs. One of the most common and reliable methods is the combination of RLDB and RLDM, that offer the option to online proctor the students during the exam and prevent them from navigating away from the exam page. Even though this approach is efficient and reliable, it might not be affordable to many HEIs as many of them are under cost-efficiency pressure where they attempt to find educational tools that would provide them with the best solutions at the cheapest cost (Buhagiar \& Leo, 2018). On the other hand, there are HEIs that cannot afford to pay any additional fee for an online teaching/assessment tool and the corresponding trainings their personnel need to undertake. Hence, they seek educational services that are available for free, and which will generally be less reliable.

The second possibility is to permit the student to take the exam remotely on any available platform, without the lockdown option, and simultaneously proctoring them using a video-conferencing tool like Zoom for instance. The main shortfall of this approach is that students can easily access other websites and pages on their computer, and even online communication tools like Facebook or WhatsApp since the lockdown option is not used. However, this might be overcome to some extent if the camera is well positioned to cover the whole exam setting, not only the students' faces.

Another proposed approach for online assessments in to convert the written exams into a comprehensive oral exam, where students are asked four to five questions, for instance, using a video-conferencing tool like Zoom, and their answers would measure their understanding and grades will be allocated accordingly. The assessment can also be a combination of written and oral defense to ensure consistency in students' answers and grades.

On the other hand, a different school of thought suggests that the exams should be transformed into projectbased assignment-based assessments with precise and objective rubrics. In this case the students would apply the fundamental knowledge they acquired in class to real life examples, using advanced analytical skills. However, this required the modification and adjustment of the courses' structure as well as the assessments' structure, to include more application and analytical cognitive skills. Another challenge of online teaching is to ensure students are attentive, engaged and interactive during classes, especially where classes are held live in real time (Redmond, Abawi, Brown, Henderson, \& Heffernan, 2018). In this regard, different HEIs use different tools and platform for online course delivery, which implies that they would use different techniques to keep students engaged. However, a combination of gamification tools and FC 
settings would help the instructor monitor the students' activity during the class, to subsequently incite them to be more interactive and engaged.

Other issues with the online mode of learning consist of the extent of relationship ties and interaction among students and between the students and their instructors, which tend to weaken as the contract between students themselves and with their instructor is reduced to the class sessions, and few additional meetings. In addition, the missing human and physical aspect of the face-to-face classes contributes to this tendency. Hence, it is proposed that at least a small proportion of the classes is provided in physical face to face to strengthen the relationship ties between students and their instructors. In addition, online learning requires a good internet connection and a well-functioning electronic device to effectively attend classes and attempt exams. These conditions might be challenging to students who do not have access to these services and might put their enrolment and academic performance at a disadvantage compared to the other students.

Nevertheless, COVID-19 pandemic has also provided an excellent opportunity for HEIs around the world to reflect on their academic practices for potential improvements and adjustments (IESALC, 2020). In this regard, some HEIs used the hybrid mode of course delivery, combining both online and physical face to face class learning. However, with the surge of COVID-19 pandemic, they realized that the full online learning mode was then required. Similarly, other HEIs had a plan to shift to the hybrid mode, and then the full online mode of learning in the short term. However, COVID-19 pandemic incited them to immediately shift to the full online learning mode, as the circumstances and conditions required it. Hence, this was an opportunity for HEIs around the world to update their short-term visions to successfully survive the COVID-19 repercussions.

\section{Discussion and Conclusion}

The main objective of the current study was to discuss the effect of COVID-19 pandemic on the higher education sector around the world, as well as the challenges and opportunities that resulted from its surge. Accordingly, the study invoked and highlighted various areas in the higher education sector transformation and migration towards the online learning mode, that was mainly due to the COVID-19 pandemic and its repercussions. Overall, the findings revealed that even though COVID-19 forced to the world into a global lockdown and WFH mode, and HEIs into an urgent online learning mode, it has also provided HEIs around the world with a unique opportunity to reflect on their academic practices and priorities for potential modification and adjustment. In this context, HEIs that had already implemented some level of online learning, or had a short-term plan to implement them, elegantly survived the peak of COVID-19 pandemic, while other HEIs have significantly struggled through the process, with some of them that were required to postpone their classes till the overall conditions allow them to resume physical face to face classes. HEIs are required to be constantly prepared for any unexpected circumstances as they are responsible for the future of millions of young generations of students.

On the other hand, even if the pandemic situation is cleared and the daily activities revert to "new normal" or even normal conditions, HEIs are highly advised to consider the implementation of online learning mode, or at least the hybrid mode of learning. In such cases, the learning process could be completed online, using advanced educational technologies, and the assessments can be either conducted online, or 
physically at the HEIs' premises. However, it will be certainly better to transform the assessments into well-structured project-based or case studies-based assessments, where the students can apply the fundamentals learned in class to real life examples. The assessment can also be coupled with a short oral defense where the students can confirm their understanding and mastery of the submitted work. As such, not only the assessment will be more reliable, but it will give the students the opportunity to extend their knowledge beyond the fundamental concepts learned in class.

Moreover, HEIs are highly advised to re-think about their budgets allocations and re-adjust them based on the experience and outcomes of COVID-19 pandemic. Specifically, more funds should be allocated to the investment in educational technology platforms and information technology infrastructures, especially in the current era, where technology is been progressing and developing at a fast pace. The COVID-19 experience clearly showed that many HEIs were at a disadvantage due to the unpreparedness in terms of technological tools in general, and educational technology.

Finally, future studies are recommended to investigate the students' academic performance and learning engagement prior and empirically and comprehensively after the migration to online learning. This will allow HEIs' managers to customize the learning experience in an efficient manner that would benefit all the participants in the learning experience. In addition, they are also recommended to investigate the effectiveness and significance of the educational technology tools, and the online learning-compatible approaches like gamification and FC in improving students' performance class engagement and interaction. This will provide important insights to the teaching faculties on the best ways to optimize the use of these tools to maximize the students' learning experience and performance.

\section{References}

Al Lily, A.E., Ismail, A.F., Abunasser, F.M. \& Alqahtani, R.H.A. (2020). Distance learning as a response to pandemics: Coronavirus and Arab cultures. Technology in Society, 63(1), 1-11.

Alokluk, J.A. (2018). The Effectiveness of Blackboard System Uses and Limitations in Information Management. Intelligent Information Management, 10(1), 133-149.

Alomari, I., Al-Samarraie, H., \& Youssef, R. (2019). The role of gamification techniques in promoting student learning: A review and synthesis. Journal of Information Technology Education Research, 18(1), 395-417.

Alshamsi, A., Mohaidat, J., Al Hinai, N., \& Samy, A. (2020). Instructional and business continuity amid and beyond COVID-19 outbreak: A case study from Higher Colleges of Technology. International Journal of Higher Education, 9(6), 118-135.

Antonaci, A., Klemke, R. \& Specht, M. (2019). The effects of gamification in online learning environments: A systematic literature review. Informatics, 32(6), 1-22.

Arnold-Garza, S. (2014). The flipped classroom teaching model and its use for information literacy instruction. Communications in Information Literacy, 8(1), 7-22.

Buhagiar, T., \& Leo, C. (2018). Does gamification improve academic performance? Journal of Instructional Pedagogies, 20(1), 1-6.

Bradford, P., Porciello, M., Balkon, N., \& Backus, D. (2007). The Blackboard learning system: The be all and end all in educational instruction. The Journal of Educational Technology Systems, 35(1), 301-314.

Compeau, D.R., \& Higgins, C.A. (1995). Computer self-efficacy: Development of a measure and initial test. MIS Quarterly, 19(2), 189-211. 
Deterding, S., Dixon, D., Khaled, R., \& Nacke, L. (2011). From game design elements to gamefulness: Defining "gamification". MindTrek 11, September $28^{\text {th }}-30^{\text {th }}$, Tampere, Finland.

Dichev, C., \& Dicheva, D. (2017). Gamifying education, what is known, what is believed and what remains uncertain: a critical review. International Journal of Educational Technology in Higher Education, 14(9), 1-36.

Gonzalez-Gonzalez, C.S., Infante-Moro, A., \& Infante-Moro, J. (2020). Implementation of E-proctoring in online teaching: A study about motivational factors. Sustainability, 12(1), 1-13.

Hai-Jew, S. (2013). Open-source technologies for maximizing the creation, deployment, and use of digital resources and information. IGI Global, Pennsylvania

He, H., \& Harris, L. (2020). The impact of COVID-19 pandemic on corporate social responsibility and marketing philosophy. Journal of Business Research, 116(1), 176-182.

Hung, A.C.Y., Zarco, E., Yang, M., Dembicki, D., \& Kase, M. (2018). Gamification in the wild: Faculty perspectives of gamifying learning in higher education. Issues and Trends in Educational Technology, 5(2), 4-22.

IESALC (2020). COVID-19 and higher education: Today and tomorrow. Caracas: IESALC.

Information Resources Management Association (2015). Open-source technology: Concepts, methodologies, tools, and applications. IGI Global, Pennsylvania.

Lin, D.T.A., Ganapathy, M., \& Kaur. M. (2018). Kahoot! It: Gamification in higher education. Pertanika Journal of Social Science and Humanities, 26(1), 565-582.

Majuri, J., Koivisto, J., \& Hamari, J. (2018). Gamification of education and learning: A review of empirical literature. GamiFIN Conference, May $21^{\text {st }}-23^{\text {rd }}$, Pori, Finland.

Martin, L., \& Tapp, D. (2019). Teaching with Teams: An introduction to teaching an undergraduate law module using Microsoft Teams. Innovative Practice in Higher Education, 3(3), 58-66.

Novac, L. (2014). Lifelong learning with Moodle. Tenth International Scientific Conference, September $22^{\text {nd }}-25^{\text {th }}$, Dobrich.

OECD (2016). Innovating Education and Educating for Innovation: The Power of Digital Technologies and Skills. Paris: OECD Publishing.

OECD (2020). The territorial impact of COVID-19: Managing the crisis across levels of government. Paris: OECD Publishing.

Ozdamli, F., \& Asiksoy, G. (2016). Flipped classroom approach. World Journal on Educational Technology: Current Issues, 8(2), 98-105.

Redmond, P., Abawi, L., Brown, A., Henderson, R., \& Heffernan, A. (2018). An online engagement framework for higher education. Online Learning Journal, 22(1), 183-204.

Sanmugam, M. Selvarajoo, A. Ramayah, B., \& Lee, K. (2019). Use of Nearpod as interactive learning method. $13^{\text {th }}$ International Technology, Education and Development Conference, March $11^{\text {th }}$ $13^{\text {th }}$, Valencia.

Smallhorn, M. (2017). The flipped classroom: A learning model to increase student engagement not academic achievement. Student Success, 8(2), 43-53.

Thakur, G. (2015). Recent trend in ICT in education. Laxmi Book Publication, Solapur.

UNDP (2020). COVID-19 and human development: Assessing the crisis envisioning the recovery. New York: UNDP.

Urfa, M. (2018). Flipped classroom model and practical suggestions. Journal of Educational Technology and Online Learning, 1(1), 47-59.

Yildirim, I. (2017). The effects of gamification-based teaching practices on student achievement and students' attitudes towards lessons. The Internet and Higher Education, 33(1), 86-92. 